\title{
Emergence of Universal Antiretroviral Therapy Coverage in South Africa: Applying the Advocacy Coalition Framework to Refine the Narratives and Inform Epidemic Responses
}

\author{
Benjamin Momo Kadia ${ }^{1 *}$, Christian Akem Dimala ${ }^{2,3}, K^{2}$ in Pene Njefi ${ }^{4}$
}

\section{Authors' affiliations}

1. Faculty of Epidemiology and Population Health, London School of Hygiene and Tropical Medicine, London, United Kingdom

2. University Hospitals of Leicester, Leicester, United Kingdom

3. Health and Human Development (2HD) Research Network, Douala, Cameroon

4. Faculty of Public Health and Policy, London School of Hygiene and Tropical Medicine, London, United Kingdom

\section{Authors' email addresses}

BMK: benjamin.momo-kadia1@alumni.Ishtm.ac.uk

CAD: akdimch@yahoo.com

KPN: njefi kevin@yahoo.com

*Corresponding author:

Benjamin Momo Kadia; email: benjamin.momo-kadia1@alumni.Ishtm.ac.uk 


\begin{abstract}
South Africa possesses the largest anti-retroviral therapy (ART) program in the world but the path to this record was dramatic. There is scarce literature employing a comprehensive framework to explain this ART policy change and inform current policy making processes. This paper applies the Advocacy Coalition Framework (ACF) to analyse the interactions among diverse actors, institutions and networks that were associated with the ART policy change in South Africa. Post-apartheid, HIVIAIDS and AIDS-related mortality were serious public health problems. At the time, the discernible coalitions in the AIDS policy subsystem were the proscience coalition and AIDS dissidents. In view of the availability of compelling scientific evidence on the pathogenesis of HIVIAIDS, the clinical usefulness of ART, the availability of funding for national ART roll-out, strong global advocacy to reduce the cost of ART, all of these in an era when access to adequate HIV care was increasingly considered a human right, the environment to establish an appropriate ART policy for the country was conducive. However, AIDS dissidents dominated the policy agenda via their control over key institutions, the use of various dimensions of power, biasing evidence to inform policy, and promoting the activities of strong interest groups that were not in support of ART. National ART roll-out ultimately emerged as a political priority as a result of external shocks (on the ART policy subsystem) which disfavoured the dominant coalition. Failure to supplement this application of the ACF with key pubic policy concepts such as evidence use in policy, power dimensions, governance and emergence of global health networks would have led to suboptimal appraisal of the ART policy change and misinformation of similar policy making processes.
\end{abstract}

\title{
Introduction
}

The advent of antiretroviral therapy (ART) has greatly revolutionized HIV care and over the years, tremendous efforts to expand ART coverage have been observed in resource-limited settings [1]. In sub-Saharan Africa where over two-thirds of persons infected with HIV live, up to 12 million people were reported to be on treatment by 2016 [2]. This corresponded to an estimated double fold increase in ART coverage over the preceding five years [2]. With regards to South Africa, the country with the largest national ART program in the world [35], the path to national ART roll-out was extremely dramatic and even linked with the death of hundreds of thousands of persons living with HIVIAIDS [6]. Even though the country's pursuit of national ART roll-out post-apartheid has been extensively described using diverse approaches $[7,8,17,9-16]$, there is scarce literature applying a comprehensive framework to 
analyse the roles of state and non-state actors who were involved in the process of AIDS policy change. In view of this important gap in the literature and the intense ideological conflicts which characterized the quest for national ART roll-out in South Africa, this paper employs the Advocacy Coalition Framework (ACF) of Sabatier and Jenkins-Smith $[18,19]$ to analyse and summarize interactions among diverse actors, institutions and networks that were associated with AIDS policy change in South Africa. A Medline search was done using the terms 'HIV' OR 'AIDS' OR 'anti?retroviral', AND 'polic*' AND 'South Africa' and their variations, with search periods from 1981 to 2019 to gather relevant published data on and evidence of the entire ART policy change process in South Africa. The authors also draw from other essential public policy concepts to further clarify the policy analysis.

\section{Applying the Advocacy Coalition Framework (ACF) to South Africa's struggle for national antiretroviral therapy (ART) roll-out}

\section{Essential points about the ACF $[18,19]$}

The ACF proposes that a policy agenda or policy change is the result of competition among coalitions that exist within policy subsystems. A coalition comprises actors, institutions, networks or interest groups that share common fundamental belief systems regarding issues within a subsystem. Belief systems range from the way issues are perceived or framed (deep core beliefs) to solutions (policies) that should be formulated to address the issue (policy core beliefs). According to the ACF, belief systems are scarcely backed by personal interests but the exact motives for supporting specific coalitions are varied. In the long run, core beliefs tend to remain stable, but changes in secondary aspects of belief systems may occur even in the short run. Nonetheless, a shock from within (internal shock) or out of (external shock) a policy subsystem could potentially lead to adjustments in belief systems or major policy changes in favour of specific coalitions. Based on the ACF, some actors do not belong to any coalition but contribute to the policy-making process by promoting opportunities for coalitions to negotiate and come to compromises. These actors are referred to as policy brokers. Policy-oriented learning, a means by which coalitions improve their understanding of variables which are consistent with their policy cores, continuously occurs within and across coalitions.

\section{Coalitions in South Africa's AIDS policy subsystem post-apartheid}

There were two discernible coalitions in the country's AIDS policy subsystem post-apartheid. AIDS dissidents comprised the minority (yet dominant) coalition. Their deep core beliefs were that HIV is harmless and does not lead to AIDS. They also believed symptoms of AIDS were consequent to poor nutrition, poverty and ART. They strongly discouraged ART by focusing on its toxic effects. Their policy core beliefs were that improvements in nutrition 
with food such as garlic, lemon juice, and beetroots could serve as treatment for HIVIAIDS. Within the country, denialists also promoted scientifically indefensible policies by scaling-up traditional remedies, various chemicals and other alternative therapies. Members of this coalition included important members of the government like Thabo Mbeki (second postapartheid president) and some ministers notably, Tshabalala-Msimang (first post-apartheid minister of health). At the international scene, members included renowned scientists (like Peter Duesberg and David Rasnick) [20], anti-AIDS organizations such as the Alive and Well AIDS Alternatives (founded by an HIV positive activist, Christine Maggiore) and actors in the popular media notably, Neville Hodgkinson.

Advocates of science-based medicine comprised the other coalition. Their deep core beliefs were that HIV infection is caused by the virus called HIV, which is transmitted via blood and other body fluids and without appropriate treatment HIV would lead to AIDS. Their policy core beliefs were that ART had proven efficacy in the prevention and treatment of HIV and should therefore be prescribed to persons living with HIVIAIDS. They fought for the national roll-out of ART in order to reach out to the thousands of people living with HIVIAIDS and to prevent maternal to child transmission of HIV. The members of this coalition included civil society groups such as Treatment Action Campaign (TAC), some government officials like Jeff Radebe and Madlala-Routledge (from the ministry of health), scientists like William Makgoba (former leader of the Medical Research Council), the media and the South African Medical Association. At the international level, members included scientists, AIDS activists, international associations of persons living with HIVIAIDS, popular media. Several delegates at the $16^{\text {th }}$ international AIDS conference had views that matched with this coalition [21].

\section{The rise of AIDS dissidents}

The first AIDS-related deaths occurred in 1981 and 1982, but little attention was accorded to the epidemic over the following decade [22]. In 1992, civil society advocated for the creation of the National AIDS Convention which produced a national AIDS plan. Two years later, the plan was adopted by Nelson Mandela's government [8]and two members of the team that drafted the plan (Dlamini-Zuma and Tshabalala-Msimang) were appointed first postapartheid health ministers. This bottom-up approach favoured by Mr Mandela's regime to tackle HIVIAIDS appeared to be effective as more cases were detected, and the prevalence of HIV rose from $0.8 \%$ in 1990 to $4.3 \%$ in 1994 [22]. Again, such an approach in a unitary state possibly indicated the pro-democracy stance of the then regime.

From the end of 1994 to 1997, a series of events heralded AIDS denialism. First, in 1994, there was a scandal (about a poorly managed HIVIAIDS awareness play called Sarafina II) involving Dlamini-Zuma who was also opposing the introduction of ART for prevention of mother-to-child transmission of HIV. The motives for this minister's change from an 
advocate of the national AIDS plan to an opponent of ART was unclear. Then, in 1997, a chemical called virodene was being promoted by a university scientist, Olga Visser and $\mathrm{Mr}$ Mbeki (then Deputy President), with the latter declaring over media that he felt privileged to have encountered HIV-infected persons who admitted feeling better with virodene. This could only have encouraged more infected persons to take virodene and illustrates how ideological power had been used by Mr Mbeki to favour untested therapies in place of ART. However, the use of virodene was not approved by the South African Medical Control Council which, legitimately, was the drug regulatory authority of the country.

The coalition of AIDS dissidents became more evident in 1999. That year, on becoming the head of state, Mr Mbeki formed an association of AIDS dissidents. He informed the National Council of Provinces that Zidovudine (AZT), an antiretroviral drug, was toxic and he wanted clarifications on the use of the drug. In 2000, he set-up a Presidential AIDS Advisory Panel (comprising orthodox scientists and denialists). With reference to the ACF, it is not clear whether Thabo Mbeki wanted to play the policy broker (which is less plausible since he was clearly an AIDS dissident) or if it was a genuine policy-oriented learning process across coalitions although there were no evident shifts in belief systems. Whichever the scenario, the creation of this panel by the president may have been consequent to Luke's second dimension of power: it was alleged that the creation of the panel was enhanced by advise from foreign dissidents (notably, Peter Duesberg and David Rasnick) [20]. By the end of 2000, after several criticisms by the media, Mr Mbeki withdrew from public commentary on HIVIAIDS and Tshabalala-Msimang managed the AIDS policy agenda. Nonetheless, it would appear he still, though latently, spear-headed decisions on AIDS policy in favour of AIDS dissidents (Luke's second face of power). In 2001, scientific reports revealed significant numbers of AIDS-related deaths. While this could have been regarded as a policy-learning opportunity to the dissidents or an internal shock on the AIDS policy subsystem against the dissidents, the latter rather framed the information to match their core beliefs: Mr Mbeki suggested that the figures had been overestimated and the reports had to be discounted for the nation to focus on other social priorities. Such framing in the face concerning data on the burden of HIVIAIDS may be regarded as an exertion of ideological power with the intention to make the core beliefs of dissidents to prevail at all cost. And even though these reports may have truly been an attempt of technical bias to influence the AIDS policy in favour of science, statistical models had later demonstrated the strong likelihood of several thousands of persons with HIVIAIDS dying as a result of lack of access to ART [6].

The beginning of shocks on the AIDS policy subsystem 
In 2003, after a court ruling against Tshabalala-Msimang who had been resisting ART rollout, the South African cabinet announced its plan to roll-out ART in the public health sector. However, in 2005, Dr William Makgoba, an immunologist who was president of the national medical research council (MRC) and an advocate of evidence-based medicine, left the MRC. This could be interpreted as an external shock that disfavoured advocates of sciencebased medicine (to which Makgoba belonged), as the MRC became less independent. A similar weakening occurred in the Medical Control Council (MCC), but the reason for this is unclear. AIDS dissidents in the government then took advantage of these external shocks to foster technical-bias in evidence as a basis for AIDS policy-making since the country's relevant regulatory institutions (MRC and $M C C$ ) had been compromised. For example, in 2005, government supported a claim that trials on micronutrients produced by Rath Foundation (owned by Matthias Rath, a German entrepreneur) had revealed that high doses of vitamins reversed the course of HIVIAIDS [6]. As a result of this technical bias in the creation of evidence, vitamins were distributed in large quantities in place of ART. Another example which occurred much later was the distribution of an untested concoction called 'Ubhejane' via public health facilities. Although it had been reported that this concoction was associated with adverse events like liver failure and the development of resistance to ART, dissidents in the government rather decided to cherry pick and divulge unfounded information suggesting beneficial effects of 'Ubhejane'[6]. Such technical bias in the creation and selection of evidence enabled dissidents to control the AIDS policy to suit their core beliefs.

In November 2005, the Treatment Action Campaign (TAC) and the South African Medical Association (SAMA) jointly filed court papers against the Minister of Health (TshabalalaMsimang), Matthias Rath and several other AIDS denialists. They were against denialists' distributing untested products in the country [23]. After the court ruled in favour of the TAC and SAMA, Tshabalala-Msimang made public declarations suggesting that ART were toxic, adding that she was being forced to give 'poison to her people', nutrition was more beneficial, and patients had the right to choose their treatment strategies. These assertions led to confusion among persons living with HIVIAIDS and there was widespread drop of ART for scientifically indefensible remedies. As was previously illustrated, such use of power as thought-control mechanism seemed to be an important strategy used by dissidents to sustain their policy core beliefs.

\section{AIDS dissidents succumb}

The Toronto International AIDS Conference of 2006 hugely condemned Mr Mbeki and Tshabalala-Msimang over the country's AIDS policy. This, among others, prompted revolts in the African National Congress (the ruling party in South Africa since the end of apartheid) 
and the cabinet of South Africa [6]. Subsequently, the cabinet reasserted itself over presidential authority by transferring responsibility for the AIDS policy to Deputy President Mlambo-Ngcuka. This series of shocks which disfavoured AIDS dissidents was not yet over: Tshabalala-Msimang took a sick leave later in the year 2006 and the deputy health minister, Madlala-Routledge, together with interim minister of health, Jeff Radebe, who were advocates of science-based medicine took over the AIDS policy agenda. They started working with the civil society and health professionals and set the objectives of halving HIV infections and expanding ART coverage to $80 \%$ by 2011 . They also planned to restructure the National AIDS Council. However, this window of opportunity (as Kingdon's model of policy-making $[24,25]$ would refer to regarding the advocacy for national ART roll-out by advocates of science-based medicine) was shut when Tshabalala-Msimang returned from leave in 2007 and restarted countering national ART roll-out. She side-lined MadlalaRoutledge who was ultimately fired by President Mbeki. Reports also indicate that in the same year, Tshabalala-Msimang started formulating new legislations to regulate use of alternative medicine among persons living with HIVIAIDS [6]. However, in 2008, there were major changes in government, and these appeared to be the greatest external shocks which favoured the coalition of science advocates: Mr Mbeki's rule ended, and his successor removed Tshabalala-Msimang from office. Universal ART coverage then became top priority on the AIDS policy agenda. This, in unison with the pre-existing national and international efforts to scale-up ART use in the country led to the emergence of national ART roll-out in the republic of South Africa.

\section{Discussion and Conclusion}

Knowledge of the actors, context and processes involved in the AIDS policy making is key to understanding the direction of change of the policy as is the case with other policy changes. Nonetheless, historical analyses highlighting the variety of instruments that could be employed by the actors is also fundamental to elucidate the drivers of major policy changes nowadays. The ACF is generally applied to domestic contexts as its initial construct was designed to understand how different actors worked together through the policy process to implement change in the United States environmental policy [26]. In this paper, we expand the application of the framework to the transnational level by capturing various actors, networks and institutions at the international scene that actively fostered core beliefs of coalitions. It is worth mentioning, in passing, that Sabatier et al had long encouraged the application of the framework on a wider scope [19] even though this is still lacking in current literature. The paper is an important attempt to enlighten the public and policy makers on the variety of instruments and processes that can be employed in the arena of policy 
making. It also serves to inform current policy makers on the merits and demerits of employing certain policy instruments within a given context and how the interplay between governance and the use of these instruments could impact population health in each context.

Post-apartheid and for over a decade, high rates of HIVIAIDS and AIDS-related mortality constituted serious public health menaces in South Africa albeit there seemed to be very conducive environment to develop an appropriate HIVIAIDS policy based on the availability of compelling scientific evidence on the pathogenesis of HIVIAIDS and the benefits of ART, availability of funding for national ART roll-out, strong global advocacy to reduce the cost of ART [27], all of these being present in an era when inaction against HIVIAIDS was literally considered a crime $[10,28-30]$. However, dissidents who constituted the minority coalition, dominated the HIVIAIDS policy agenda via their control over key national institutions, the use of various dimensions of power, biasing evidence to inform policy, and promoting the activities of strong interest groups notably, Traditional Healers' Organization, businessmen and charlatans. National ART roll-out ultimately emerged as a political priority as a result of external shocks (changes in leadership and governance) which disfavoured the dissidents' coalition. From another perspective, the response to the public health menace posed by HIVIAIDS in South Africa could be regarded as the result of the way the menace was framed by diverse actors and institutions that had access to some form of power. Two important examples are worth citing. It was suggested that Mr Mbeki framed the menace and the proposition of rolling-out ART as the products of conspiracies spear-headed by Western societies and he therefore countered every effort to roll-out ART in his high authority as president [31]. In line with the ACF, this may have been the origin of his core belief as an AIDS dissident and slowed down national ART roll-out. On the other hand, albeit the second part of the Sarafina play received several criticisms, it can be argued that the production of such a play illustrates that its initiators had framed HIVIAIDS in South Africa as an issue requiring the use of complex biosocial interventions and not just ART for the effective control of the pandemic.

Even though the ACF is one of the most comprehensive frameworks for explaining policy change, failure to borrow from other public policy concepts such as governance and policy implementation, dimensions of power, framing of global health issues, evidence use in policy and emergence of global health networks to supplement the ACF would lead to suboptimal appraisal of the AIDS policy change and misinformation of similar policy making processes. Such complex system systems thinking approach should not only serve to better understand policy making processes but should also provide insights into the potential 
downstream effects of adopted policies and strategies to appropriately fine-tune them for population health gains.

The main limitation of this paper is that the historical analysis was not supplemented with evidence from key informant interviews and other qualitative data collection methods. This could have provided more perspectives on the policy change process and how the AIDS policy change was embraced by key stakeholders.

\section{Declarations}

\section{Ethics approval and consent to participate}

Not applicable

\section{Consent for publication}

Not applicable

\section{Competing interests}

The authors declare that they have no competing interests.

\section{Funding}

No funding was received for the publication of this manuscript.

\section{Authors' contributions}

BMK: conception of the policy analysis topic, performed the literature search and drafted the initial manuscript. CAD: critically-reviewed the manuscript, provided technical and intellectual guidance. KPN: assisted with the literature review, critically-reviewed the manuscript, and edited the final manuscript. All the authors approved the final manuscript.

\section{Availability of data and materials}

Not applicable

\section{Acknowledgements}

Not applicable

\section{References}

1. Ford N, Calmy A, Mills EJ. The first decade of antiretroviral therapy in Africa. Global Health. 2011;7:1-6.

2. Joint United Nations Programme on HIVIAIDS (UNAIDS). Global AIDS Update. 2016;

3. Shisana O. South African National HIV Prevalence, Incidence and Behaviour Survey, 2012. HSRC Press. 2014;

4. Whiteside A, Cohen J, Strauss M. Reconciling the science and policy divide: The reality of scaling up antiretroviral therapy in South Africa. South Afr J HIV Med. 2015;16:1-5. 
5. Satoh S, Boyer E. HIV in South Africa. Lancet (London, England) [Internet]. England; 2019;394:467.

6. Nattrass N. AIDS and the scientific governance of medicine in post-apartheid South Africa. Afr Aff (Lond). 2008;107:157-76.

7. Fourie P, Meyer M. The politics of AIDS denialism: South Africa's failure to respond. Polit. AIDS Denialism South Africa's Fail. to Respond. 2010.

8. Gomez EJ, Harris J. Political repression, civil society and the politics of responding to AIDS in the BRICS nations. Health Policy Plan. England; 2016;31:56-66.

9. Nattrass N. South Africa's "rollout" of highly active antiretroviral therapy: a critical assessment. J Acquir Immune Defic Syndr. United States; 2006;43:618-23.

10. Forman L. What contribution have human rights approaches made to reducing AIDSrelated vulnerability in sub-Saharan Africa? Exploring the case study of access to antiretrovirals. Glob Health Promot. England; 2013;20:57-63.

11. Jackson KE, Jackson WLJ. The right to health and the nevirapine case in South Africa. N Engl J Med. United States; 2003;348:2470-1.

12. Sun J, Boing AC, Silveira MPT, Bertoldi AD, Ziganshina LE, Khaziakhmetova VN, et al. Efforts to secure universal access to HIVIAIDS treatment: a comparison of BRICS countries. J Evid Based Med. England; 2014;7:2-21.

13. Nunn A, Dickman S, Nattrass N, Cornwall A, Gruskin S. The impacts of AIDS movements on the policy responses to HIVIAIDS in Brazil and South Africa: a comparative analysis. Glob Public Health. England; 2012;7:1031-44.

14. Gow JA. The adequacy of policy responses to the treatment needs of South Africans living with HIV (1999-2008): a case study. J Int AIDS Soc. Switzerland; 2009;12:37.

15. Parkhurst JO, Lush L. The political environment of HIV: lessons from a comparison of Uganda and South Africa. Soc Sci Med. England; 2004;59:1913-24.

16. Schneider H, Stein J. Implementing AIDS policy in post-apartheid South Africa. Soc Sci Med [Internet]. England; 2001;52:723-31.

17. Benatar SR. Health care reform and the crisis of HIV and AIDS in South Africa. N Engl J Med [Internet]. United States; 2004;351:81-92.

18. Sabatier PA, Jenkins-Smith H. The Advocacy Coalition Framework: An Assessment. Theor Policy Process. 1999.

19. Sabatier PA, Weible CM. The Advocacy Coalition Framework: Innovations and Clarifications. Theor. Policy Process. 1999.

20. Cherry M. Are AIDS dissidents advising South Africa?. Nature [Internet]. England; 2000;404:216.

21. Gayle H, Wainberg MA. Impact of the 16th International Conference on AIDS: can these 
conferences lead to policy change?. Retrovirology [Internet]. England; 2007;4:13.

22. Simelela NP, Venter WDF. A brief history of South Africa's response to AIDS. South African Med J. 2014;104:249-51.

23. Report W. Court case shines spotlight on South African AIDS policy A maverick physician who believes that vitamins can stave off AIDS is being sued in South Africa after accusing an AIDS advocacy group of being a front for drug firms. The case is also being seen. 2005;1916-7.

24. Rawat P, Morris JC, Knutsen WL, Weiner T, David CP, Kingdon JW, et al. Kingdon's "Streams" Model at Thirty: Still Relevant in the 21st Century? Polit Policy. 2016;

25. Durant RF. Agendas, Alternatives, and Public Policy: Lessons from the U.S. Foreign Policy Arena. J Public Policy. 1989;

26. Sabatier PA. An advocacy coalition framework of policy change and the role of policyoriented learning therein. Policy Sci. 1988;

27. Muula AS. South Africa's national response to HIV and AIDS treatment: popular media's perspective. Croat Med J. Croatia; 2008;49:114-9.

28. Forman L. The imperative to treat: the South African state's constitutional obligations to provide antiretroviral medicines. Health Law Rev. Canada; 2003;12:9-15.

29. Forman L. Ensuring Reasonable Health: health rights, the judiciary, and South African HIVIAIDS policy. J Law Med Ethics. United States; 2005;33:711-24.

30. London L. Human rights and public health: dichotomies or synergies in developing countries? Examining the case of HIV in South Africa. J Law Med Ethics. United States; 2002;30:677-91

31. Helen Schneider (2002) On the fault-line: The politics of AIDS policy in contemporary South Africa, African Studies, 61:1, 145-167, DOI: 10.1080/00020180220140118. 